\title{
Novel role of the nitrite transporter NirC in Salmonella pathogenesis: SPI2-dependent suppression of inducible nitric oxide synthase in activated macrophages
}

Correspondence

Dipshikha Chakravortty

dipa@mcbl.iisc.ernet.in

Received 28 March 2009

Revised 4 June 2009

Accepted 5 June 2009
Priyanka Das, Amit Lahiri, Ayan Lahiri and Dipshikha Chakravortty

Center for Infectious Disease Research and Biosafety Laboratories, Department of Microbiology and Cell Biology, Indian Institute of Science, Bangalore 560012, India

\section{INTRODUCTION}

Salmonella enterica serovar Typhimurium is a broad-hostrange pathogen that causes self-limiting gastroenteritis in immunocompetent humans. Mouse infection by Salmonella Typhimurium constitutes a model for the systemic syndrome associated with nontyphoidal salmonellosis in immunodeficient people. In mice, Salmonella Typhimurium proliferates in the phagocytic cells (Miller et al., 1995). Macrophages express inducible nitric oxide synthase (iNOS), which then catalyses the generation of nitric oxide (NO) upon stimulation with interferon gamma $(\mathrm{IFN}-\gamma)$ and various other agents including Salmonella (Brett et al., 2008; Chakravortty \& Hensel, 2003; Cherayil \&

Abbreviations: BMDM, bone-marrow-derived macrophages; FBS, fetal bovine serum; IFN- $\gamma$, interferon gamma; iNOS, inducible nitric oxide synthase; JAK-STAT, Janus kinase/signal transducer and activator of transcription; L-NIL, L-N $N^{6}$-iminoethyllysine; MLN, mesenteric lymph nodes; NED, $\mathrm{N}$-(naphthyl)ethylenediamine dihydrochloride; RNS, reactive nitrogen species; ROI, reactive oxygen intermediates; SOCS-3, suppressor of cytokine signalling-3; SPI2, Salmonella pathogenicity island 2.

Three supplementary tables and three supplementary figures are available with the online version of this paper.
Antos, 2001; MacMicking et al., 1997; Stuehr, 1997; Xie \& Nathan, 1994). High NO production suppresses the growth of many intracellular pathogens such as Leishmania major (Evans et al., 1993), Toxoplasma gondii (Suzuki et al., 1988), Mycobacterium bovis (Hanano \& Kaufmann, 1995) and Salmonella (Mastroeni et al., 2000; Vazquez-Torres et al., 2000). The antimicrobial property of NO is due to its ability to bring about widespread damage to DNA, proteins and lipids. In order to survive and thrive in the hostile environment of the host, Salmonella employs various strategies to avoid and persist in the presence of antimicrobial radicals such as NO (Lahiri et al., 2008a) and the subsequently produced reactive nitrogen species (RNS). For example, Salmonella can prevent co-localization of the Salmonella-containing vacuole with iNOS in a SPI2 (Salmonella pathogenicity island 2)-dependent manner, protecting itself from the NO stress (Chakravortty et al., 2002).

To counteract host nitrosative stress, Salmonella has evolved many RNS-metabolizing enzymes, such as the flavohaemoglobin HmpA (Bang et al., 2006) for aerobic detoxification of NO, and the flavorubredoxin NorV and 
the periplasmic cytochrome $c$ NrfA nitrite reductase for anaerobic detoxification of NO (Mills et al., 2008). In addition, Salmonella has the nir operon, which is predicted to encode an NADH-dependent nitrite reductase (NirBD), which is potentially able to reduce nitrite to ammonia. The third gene of the nir operon, nirC, codes for a potential nitrite transporter, which is predicted to be a polytopic membrane protein having six transmembrane helices. Its homologue in Escherichia coli is induced during anaerobic growth in the presence of high concentrations of nitrite and is required for nitrite uptake (Clegg et al., 2002). Although several studies have focused on the roles of other NO stress-combating genes in Salmonella, the role of NirC in this context has remained unknown.

IFN- $\gamma$, a very important secretory cytokine, plays a complex and central role in the resistance of mammalian hosts to pathogens. Over 200 genes are known to be regulated by IFN- $\gamma$ via the Janus kinase/signal transducer and activator of transcription (JAK/STAT) signalling pathway. IFN- $\gamma$ transcriptionally co-induces iNOS and two additional enzymes involved in substrate (L-arginine) and cofactor (tetrahydrobiopterin) synthesis for $\mathrm{NO}$ generation (Boehm et al., 1997). On the other hand, SpiC, one of the crucial secreted virulence factors encoded by SPI2, inhibits IFN- $\gamma$ signalling by inducing the host factor SOCS-3 (suppressor of cytokine signalling-3) (Uchiya et al., 1999; Uchiya \& Nikai, 2005). Thus, the level of SpiC in activated macrophages dictates the outcome of Salmonella infection by regulating IFN- $\gamma$ induced iNOS expression.

In the study reported here, we have shown that the NO response and iNOS induction in IFN- $\gamma$-activated macrophages (both pre- and post-treatment) is downregulated following infection with wild-type Salmonella in a nirCdependent manner. We further demonstrate that the nirC mutant shows a higher level of SPI2 repression under nitrosative stress and elicits an increased phosphorylation of STAT-1 in IFN- $\gamma$-activated macrophages. This leads to increased iNOS induction and thereby controls the NO response of the host macrophages. This study is believed to be the first to show that NirC is a major nitrite transporter in Salmonella and is required for its virulence in mice. It further demonstrates the intricate relationship between NirC and SPI2 and its importance in determining the fate of Salmonella pathogenesis.

\section{METHODS}

Bacterial strains, plasmids and growth conditions. The strains and plasmids used for this study are listed in Supplementary Table S1, available with the online version of this paper. The wild-type (WT) $S$. enterica serovar Typhimurium strain 12023 used was a kind gift of Professor Michael Hensel, Max von Pettenkofer-Institute for Hygiene and Medizinische Mikrobiologie, Germany. The bacterial cultures were grown at $37{ }^{\circ} \mathrm{C}$ in Luria broth (LB) in the presence of nalidixic acid, carbenicillin or kanamycin at $50 \mu \mathrm{g} \mathrm{ml}^{-1}$. Heat-killed bacteria were prepared by heating the cultures at $80{ }^{\circ} \mathrm{C}$ for $20 \mathrm{~min}$.
Preparation of bone-marrow-derived macrophages (BMDM). As described by Pan et al. (2006), femurs were collected aseptically from mice, and after removal of muscle, the ends of the bones were cut off and the marrow was flushed out. The cells were centrifuged at 1000 r.p.m. for $10 \mathrm{~min}$ and resuspended in Dulbecco's modified Eagle medium (DMEM; Gibco) [with $4.5 \mathrm{~g}$ D-glucose and $110 \mathrm{mg}$ sodium pyruvate per litre and with the addition of $30 \%$ L929 cellconditioned medium (see below), $10 \%$ heat-inactivated fetal bovine serum (FBS), $2 \mathrm{mM}$ L-glutamine, $100 \mathrm{U}$ penicillin $\mathrm{ml}^{-1}, 100 \mu \mathrm{g}$ streptomycin $\mathrm{ml}^{-1}$ ], and $30 \mathrm{ml}$ aliquots were added to $150 \mathrm{~mm}$-style non-tissue-culture-treated dishes. The plate was placed in a tissue culture incubator in $10 \% \mathrm{CO}_{2}$ at $37{ }^{\circ} \mathrm{C}$, and after 4 days $10 \mathrm{ml}$ additional medium was added. When the cells reached confluence, the medium was removed, and the cells were washed once and detached by a 15 min exposure to ice-cold PBS. The detached cells were suspended by pipetting, centrifuged at 1000 r.p.m. for $5 \mathrm{~min}$, resuspended in DMEM-L929 conditioned medium, and plated in tissue culture plates. The cells were observed to be $>90 \%$ CD11b positive by fluorescence-activated cell sorting analysis. The BMDM were plated at $1 \times 10^{6}$ cells ml $^{-1}$ in 24 -well tissue culture plates $6 \mathrm{~h}$ prior to use in experiments.

The L929 cell line was a kind gift of Professor M. S. Shaila, Department of Microbiology, Indian Institute of Science, Bangalore, India. L929 conditioned medium was produced by plating L929 cells in $75 \mathrm{~cm}^{2}$ tissue culture flasks at an initial density of $1 \times 10^{6} \mathrm{cells} \mathrm{ml}^{-1}$ in DMEM (high glucose) supplemented with $10 \%$ non-heated FBS, $2 \mathrm{mM}$ L-glutamine, and penicillin/streptomycin as described above. After 5 to 7 days in culture, when the adherent cells were fully confluent, the culture supernatant was centrifuged at 2000 r.p.m. for $10 \mathrm{~min}$, aliquoted and stored at $-20{ }^{\circ} \mathrm{C}$.

Cell culture and bacterial infection. The murine macrophage-like cell line RAW264.7 was a kind gift of Professor Anjali Karande, Department of Biochemistry, Indian Institute of Science, Bangalore, India. RAW264.7 cells were maintained in a $37{ }^{\circ} \mathrm{C}$ incubator with $5 \%$ $\mathrm{CO}_{2}$ in DMEM (Sigma) supplemented with $10 \%$ heat-inactivated FBS (Sigma).

Bacterial infection of macrophages was performed as described previously (Chakravortty et al., 2002; Lahiri et al., 2008b). Briefly, the strains were grown to stationary phase in LB with the respective antibiotic. The $\mathrm{OD}_{600}$ of the cultures was adjusted with LB to 0.3 and the bacteria were washed once with PBS. Appropriate dilutions of the bacterial cultures were made in cell culture medium and added to the macrophage cells growing in tissue culture plates at different multiplicities of infection (m.o.i.) as stated in the figure legends. Bacteria were centrifuged onto the cells at $500 \mathrm{~g}$ for $5 \mathrm{~min}$. After infection for $25 \mathrm{~min}$, cells were washed three times with PBS and incubated for $1 \mathrm{~h}$ in the cell culture medium containing $25 \mu \mathrm{g}$ gentamicin $\mathrm{ml}^{-1}$ (Sigma). The medium was replaced with medium containing $10 \mu \mathrm{g}$ gentamicin $\mathrm{ml}^{-1}$ for the rest of the experiment.

For the enumeration of the intracellular bacteria, macrophages were washed three times with PBS, lysed with $0.1 \%$ Triton X-100 for $10 \mathrm{~min}$ at room temperature, and serial dilutions were plated onto LB agar with the respective antibiotics. In some experiments, chloramphenicol $\left(15 \mu \mathrm{g} \mathrm{ml}^{-1}\right)$, recombinant murine IFN- $\gamma$ (Peprotech, $100 \mathrm{U} \mathrm{ml}^{-1}$ ), aminoguanidine (Sigma, $100 \mu \mathrm{M}$ ) or L-NIL (L- $N^{6}$ iminoethyllysine; Calbiochem, $10 \mu \mathrm{M}$ ) was added to the cells along with $10 \mu$ g gentamicin $\mathrm{ml}^{-1}$.

Construction of the nirC mutant Salmonella strain. The nirC (STM 3476) mutation was engineered in Salmonella Typhimurium following the one-step deletion strategy as described by Datsenko \& Wanner (2000). Briefly, transformants carrying a red helper plasmid (pKD46) were grown in LB with ampicillin and $10 \mathrm{mM} \mathrm{L}$-arabinose at $30{ }^{\circ} \mathrm{C}$ to an $\mathrm{OD}_{600}$ of $0.35-0.4$ and then made electrocompetent by 
washing three times with ice-cold $10 \%(\mathrm{v} / \mathrm{v})$ glycerol and MilliQ water. PCR product containing the kanamycin-resistance gene (from plasmid pKD4) flanked by sequences upstream and downstream of nirC was obtained with the sets of primers described in Supplementary Table S2. This DNA was then electroporated into Salmonella Typhimurium carrying pKD46. The nirC mutant was selected by kanamycin resistance and confirmed by PCR using the confirmatory primers. In the knockout strain, a $1.5 \mathrm{~kb}$ band was amplified whereas in the WT strain with confirmatory primers a gene-specific band of 800 bp was observed.

Construction of the nirC-complemented strain and spiC-overexpressing strain. DNA extracted from WT Salmonella Typhimurium was used as a template to amplify the nir $C$ gene or the spiC gene using primers listed in Supplementary Table S2. The amplified product was purified and the inserts along with vector pQE60 were digested with BamHI and HindIII. The vector and insert were mixed at $1: 3$ molar concentrations and ligated at $16{ }^{\circ} \mathrm{C}$ for $16 \mathrm{~h}$. The vector-containing inserts were then transformed into $E$. coli competent cells and plated on LB-carbenicillin plates after $1 \mathrm{~h}$ incubation in LB medium. The colonies were screened for plasmids having the appropriate insert by restriction digestion, and the purified plasmid containing nirC was then transformed into $\triangle$ nirC electrocompetent cells. The spiC-containing plasmid was transformed in both the WT and $\Delta$ nirC background.

Determination of the nitrite concentration. Nitrite $\left(\mathrm{NO}_{2}^{-}\right)$ accumulation in the supernatants of cultured macrophages, used as an indicator of NO production, was measured by the Griess reaction with sodium nitrite as a standard. A $50 \mu \mathrm{l}$ sample of the supernatant was incubated for $10 \mathrm{~min}$ with $50 \mu \mathrm{l}$ of a solution containing $\mathrm{N}$ (naphthyl)ethylenediamine dihydrochloride (NED) (0.01\%) and sulfanilamide $(0.1 \%)$ in $5 \%$ phosphoric acid. The absorbance was then measured at $540 \mathrm{~nm}$.

Nitrite uptake assay. Nitrite uptake was determined by measuring nitrite disappearance from the uptake mixture as described by Wu \& Stewart (1998). Assay mixtures contained cell suspension $\left(1 \times 10^{8}\right.$ bacteria), $40 \mathrm{mM}$ glucose, and $80 \mathrm{mM}$ MOPS/NaOH buffer ( $\mathrm{pH} 8.0$ ) in a final volume of $5.0 \mathrm{ml}$. Assays were initiated by adding $\mathrm{NaNO}_{2}$ at a final concentration of $75 \mu \mathrm{M}$. The assay tube $(5 \mathrm{ml})$ was incubated at $37{ }^{\circ} \mathrm{C}$ with shaking. At defined time intervals, a $100 \mu$ sample of the culture was mixed with $50 \mu 11 \%(\mathrm{w} / \mathrm{v})$ sulphanilamide in $1 \mathrm{M}$ $\mathrm{HCl}$ and $50 \mu \mathrm{l} 0.01 \%(\mathrm{w} / \mathrm{v})$ naphthylethylene diamine dihydrochloride. The presence of nitrite was indicated by the appearance of a dark pink colour that developed immediately. The concentration of nitrite in the supernatant was determined by measuring the absorbance at $540 \mathrm{~nm}$ using sodium nitrite as standard. Uptake rates (micromoles of nitrite produced per minute per $10^{8}$ bacteria) were determined until $16 \mathrm{~h}$ of growth.

Construction of the nirc and spic reporter plasmids. The pHG86 plasmid, which carries a promoterless lacZ gene downstream from a unique MCS site, was used for cloning of the promoter constructs. DNA extracted from WT bacteria was used as a template to amplify the nirC promoter (500 bp) or spiC promoter (500 bp) using primers listed in Supplementary Table S2. The amplified products were purified using the Eppendorf 'Gel Cleanup' kit and the insert along with vector pHG86 was digested with EcoRI and BamHI. The vector and insert were mixed at $1: 3$ molar concentrations and ligated at $16{ }^{\circ} \mathrm{C}$ for $16 \mathrm{~h}$. The vector-containing insert was then transformed into $E$. coli $\mathrm{DH} 5 \alpha$ competent cells, which were plated on LB-ampicillin plates after $1 \mathrm{~h}$ incubation in SOC medium. The colonies were screened for plasmids with the appropriate insert, and isolated plasmids were then transformed into either the WT or the $\Delta$ nirC strain.
Determination of the effects of acidified nitrite on nirC promoter activity. WT Salmonella Typhimurium harbouring either the nirC: : lacZ promoter construct or the empty vector were grown overnight in $\mathrm{LB}$ and were further subcultured at $37^{\circ} \mathrm{C}$ in a shaker incubator until they reached an $\mathrm{OD}_{600}$ of 0.4. The $\mathrm{NO}$ donor $\mathrm{NaNO}_{2}$ (Sigma, freshly prepared in distilled water) and $\mathrm{H}_{2} \mathrm{O}_{2}$ (Sigma) were used to determine the effects of RNS and ROI (reactive oxygen intermediates) stress on nirC transcription. The NO donor was added to LB at pH 5.0 along with $100 \mu \mathrm{l}$ samples of exponential-phase Salmonella culture adjusted to the same $\mathrm{OD}_{600}(0.2)$. After 1,3 and $9 \mathrm{~h}$ of exposure, equal $\mathrm{OD}_{600}(0.3)$ aliquots of different samples were examined for $\beta$-galactosidase activity and serial dilution was performed for enumeration of bacteria. Five hundred microlitres of OD-adjusted culture of each sample was centrifuged at $10000 \mathrm{~g}$. The pellet was resuspended in Z-buffer $\left(\mathrm{Na}_{2} \mathrm{HPO}_{4}, 60 \mathrm{mM}\right.$; $\mathrm{NaH}_{2} \mathrm{PO}_{4}$, $40 \mathrm{mM}$; KCl, $10 \mathrm{mM} ; \mathrm{MgSO}_{4} .7 \mathrm{H}_{2} \mathrm{O}, 1 \mathrm{mM} ; \beta$-ME, $50 \mathrm{mM}$; pH 7.0). Then $20 \mu \mathrm{l}$ chloroform and $10 \mu \mathrm{l} 0.1 \%$ SDS were added to the resuspended pellet along with $200 \mu \mathrm{l} o$-nitrophenyl $\beta$-D-galactopyranoside (ONPG, Sigma) $\left(4 \mathrm{mg} \mathrm{ml}^{-1}\right)$. After $1 \mathrm{~h}$ incubation in the dark at $28{ }^{\circ} \mathrm{C}, 500 \mu \mathrm{l} 1 \mathrm{M} \mathrm{NaCO}_{3}$ was used to stop the reaction. Finally, the absorbance was measured at $420 \mathrm{~nm}$. $\beta$-Galactosidase activity (Miller units) was expressed relative to the respective empty vector controls.

Western blot analysis. RAW264.7 cells were seeded in 6-well plates $\left(5 \times 10^{5}\right.$ cells per well). At $12 \mathrm{~h}$ after infection or treatment, cells were scraped from the bottom of the wells, lysed in SDS-PAGE sample buffer and boiled for $5 \mathrm{~min}$ at $95{ }^{\circ} \mathrm{C}$. Aliquots containing equal amount of protein $(100 \mu \mathrm{g})$ were loaded onto $10 \%$ gel and transferred onto the nitrocellulose membrane using a mini-gel transfer apparatus (Bio-Rad). The membranes were treated with $5 \%$ skimmed milk solution for $1 \mathrm{~h}$ to block non-specific binding and then incubated for $2 \mathrm{~h}$ with rabbit polyclonal antibody against mouse iNOS (Sigma-Aldrich; 1:10 000), rabbit polyclonal antibody against mouse P-STAT-1 (Cell Signalling; 1:1000) or rabbit polyclonal antibody against mouse $\beta$-actin (Sigma; $1: 1000$ ). The blots were further treated with goat anti-rabbit IgG-horseradish peroxidase conjugate (AP-Biotech, 1:2000) for $2 \mathrm{~h}$. The immune complexes on the blots were detected with enhanced chemiluminescence substrate (Perkin Elmer) and exposed to Eastman Kodak XAR X-ray film.

Determination of the effects of NO on SPI2 expression. SPI2 expression was induced by culturing Salmonella Typhimurium in low-osmolarity $\left(8 \mu \mathrm{M} \mathrm{MgCl} \mathrm{Mg}_{2}\right) \mathrm{N}$ salts mediume (Deiwick et al., 1999). Briefly, strains harbouring the spiC: lacZ promoter construct were grown overnight in high-magnesium $\mathrm{N}$ salts medium $(5 \mathrm{mM}$ $\mathrm{KCl}, 7.5 \mathrm{mM}\left(\mathrm{NH}_{4}\right)_{2} \mathrm{SO}_{4}, 0.5 \mathrm{mM} \mathrm{K}_{2} \mathrm{SO}_{4}, 1 \mathrm{mM} \mathrm{KH_{2 }} \mathrm{PO}_{4}, 38 \mathrm{mM}$ glycerol, $0.1 \%$ Casamino acids supplemented with $10 \mathrm{mM} \mathrm{MgCl}_{2}$ and $100 \mathrm{mM}$ Tris/HCl), $\mathrm{pH}$ 7.6. The bacteria were subcultured in this medium and grown at $37^{\circ} \mathrm{C}$ in a shaker incubator until they reached an $\mathrm{OD}_{600}$ of 0.5 . SPI2 expression was induced by switching the bacteria to $8 \mu \mathrm{M} \mathrm{MgCl}_{2} \mathrm{~N}$ salts medium, $\mathrm{pH}$ 6.9. The $\mathrm{NO}$ donor $\mathrm{NaNO}_{2}$ (Sigma, freshly prepared in distilled water) was used to determine the effect of RNS on SPI2 transcription. The NO donor was added to fresh $8 \mu \mathrm{M} \mathrm{MgCl} 2 \mathrm{~N}$ salts medium, $\mathrm{pH} 5.0$, along with $100 \mu \mathrm{l}$ of OD-adjusted Salmonella Typhimurium cultures that had been grown for $1 \mathrm{~h}$ in $8 \mu \mathrm{M} \mathrm{MgCl}_{2} \mathrm{~N}$ salts medium. The expression of the spiC: : lac Z promoter construct was quantified spectrophotometrically as $\beta$-galactosidase activity using the substrate ONPG (Sigma) as described above. $\beta$-Galactosidase activity was expressed as fold decrease in Miller units from the control values where nitrite was not added.

Synthesis of SPI2 cDNA from bacterial cultures. Total RNA was isolated from the bacterial cultures grown in $8 \mu \mathrm{M} \mathrm{MgCl}_{2} \mathrm{~N}$ salts medium after exposure to nitrite stress at pH 5.0 as described before. The samples were resuspended in TRIzol reagent (Sigma) and the 
total RNA was isolated according to the manufacturer's protocol. Complementary cDNA was synthesized at $42{ }^{\circ} \mathrm{C}$ for $30 \mathrm{~min}$ using MMLV reverse transcriptase (Promega) and was used as template for standard PCR with gene-specific forward and reverse primers as indicated in Supplementary Table S2.

Localization of nitrotyrosine residues by fluorescence microscopy. The formation of peroxynitrite molecules in the IFN- $\gamma$ activated macrophages was determined by standard immunocytochemical methods. Cells infected with WT Salmonella Typhimurium or the nirC mutant were washed free of medium and the cells were fixed for $10 \mathrm{~min}$ in paraformaldehyde $(3.5 \%)$ at room temperature and washed in PBS. Fixed cells were then incubated for $1 \mathrm{~h}$ with rabbit anti-mouse nitrotyrosine IgG (Upstate Biotechnology) diluted $1: 250$ and mouse anti-LPS antibody $(1: 500$, Hytest $)$ in PBS containing $2 \%$ BSA, $2 \%$ goat serum and $0.2 \%$ saponin. The cells were then washed three times in PBS and incubated in identical conditions with goat anti-rabbit IgG conjugated to Cy5 (Jackson Laboratory, $1: 100$ ) and goat anti-mouse IgG conjugated to Cy2 (Jackson Laboratory, $1: 100$ ) for $1 \mathrm{~h}$. Samples were viewed with a confocal laser-scanning microscope equipped with an argon laser (Zeiss).

\section{Determination of the nirC and the spic promoter activity in the activated RAW264.7 cell line. RAW264.7 cells were seeded into 24- well plates $\left(2 \times 10^{5}\right.$ cells; three wells per time point $)$ and were infected with WT Salmonella Typhimurium carrying either the nirC or the spiC promoter and with the nirC mutant carrying the spiC: : lac $Z$ promoter construct. Cells were also infected with WT Salmonella carrying pHG86 empty vector as a control. At selected time points post-infection, as described by Szeto et al. (2009), cells were washed twice with PBS and harvested using a total of $1 \mathrm{ml}$ ice-cold lysis buffer per well (1\% Triton X-100, $0.1 \%$ SDS, $1 \mathrm{mM}$ PMSF, $5 \mathrm{mM} \mathrm{NaF}$, $5 \mathrm{mM} \mathrm{NaV}, 10 \mu \mathrm{g}$ aprotinin $\mathrm{ml}^{-1}, 1 \mu \mathrm{g}$ leupeptin $\mathrm{ml}^{-1}, 10 \mu \mathrm{g}$ pepstatin $\mathrm{ml}^{-1}$ ). A $200 \mu \mathrm{l}$ sample of cell lysate from each time point was used to enumerate intracellular bacteria by dilution plating. The remaining $800 \mu \mathrm{l}$ of cell lysate was centrifuged at $10000 \mathrm{~g}$ for $3 \mathrm{~min}$, and the pellet was resuspended in $50 \mu \mathrm{l}$ PBS and mixed with $13 \mu \mathrm{l}$ chloroform. The expression of the spiC: : lacZ promoter construct in different bacterial pellets was quantified spectrophotometrically as $\beta$-galactosidase activity using the substrate ONPG (Sigma). $\beta$ - Galactosidase activity was expressed as fold increase compared to control infection.}

Mouse experiments. Six- to eight-week-old NOS $^{-1-}$ mice (B6.129 P2-Nos $2<$ tm1Lau $>/$ J, Jackson Laboratory) and congenic B6 mice and $\mathrm{BALB} / \mathrm{c}$ mice were maintained under specific-pathogen-free conditions in the Central Animal Facility, Indian Institute of Science, Bangalore, India. All the procedures with animals were carried out as approved by the animal ethics committee of the Institute. Bacterial strains were grown with shaking overnight at $37^{\circ} \mathrm{C}$, centrifuged, washed, resuspended to an appropriate concentration in sterile PBS and administered to mice at the indicated doses. For the organ infiltration experiment, 5 days after infection, spleens were taken aseptically. The organs were weighed and homogenized in $1 \mathrm{ml}$ PBS The homogenate was centrifuged and plated at different dilutions to determine the number of bacteria.

The competitive index assays (Beuzon \& Holden, 2001) were performed by oral infection of mice with mixtures of the WT and $\Delta$ nirC or the WT and complemented $\triangle$ nirC strain in a $1: 1$ ratio in an inoculum of $0.5 \times 10^{6}$ bacteria. After 5 days of infection, homogenized samples of liver, spleen and MLN of infected mice were plated on different antibiotic plates and the competitive index of the $\Delta$ nirC strain was calculated in two independent experiments. As a control experiment, the competitive indices of a different WT strain were calculated in the same way.
Serum nitrite assays. Mice sera were collected from WT- or $\Delta$ nirCinfected mice. Each group consisted of three mice. The serum was deproteinized to reduce turbidity by precipitation using methanol/ diethyl ether. Experiments were performed at room temperature. A nitrite standard solution was serially diluted $(200-1.6 \mu \mathrm{M})$ in duplicate in a 96-well, flat-bottomed polystyrene microtitre plate (Polylab). The diluting medium was used as standard blank. After loading the plate with samples $(100 \mu \mathrm{l})$, addition of $\mathrm{VCl}_{3}(100 \mu \mathrm{l})$ to each well was rapidly followed by addition of the Griess reagents, sulfanimide $(100 \mu \mathrm{l})$ and NED $(100 \mu \mathrm{l})$. The absorbance at $540 \mathrm{~nm}$ was measured in a plate reader after incubation for $30 \mathrm{~min}$ in the dark (Miranda et al., 2001).

Statistical analysis and software. Each assay was repeated at least three times. In vitro data were analysed by paired $t$ test (two sample, equal variance) and $P$-values below 0.05 were considered significant. FACS data were plotted and analysed using WinMDI 2.9 software. Results of mouse challenge studies were evaluated by using MannWhitney $U$ tests from the GraphPad Prism 4.0 software. Differences between experimental groups were considered significant for $P<0.05$. Immunoblots and gels were quantified using Multi Gauge V2.3 software.

\section{RESULTS}

\section{NirC in Salmonella Typhimurium is a conserved membrane-spanning nitrite transporter}

In silico analysis predicted that the NirC protein in Salmonella has six membrane-spanning domains as known in E. coli. Bioinformatics analysis against non-redundant protein databases revealed that several bacterial proteins share significant homology with NirC. All of them are known nitrite or formate transporters from different bacteria. More precise comparison of $\mathrm{NirC}$ in all Salmonella species also revealed its conserved nature (Supplementary Fig. S1).

\section{Infection of IFN- $\gamma$-activated RAW264.7 macrophages with WT Salmonella Typhimurium suppresses IFN- $\gamma$-induced NO synthesis in a nirC- dependent manner}

Macrophages play a critical role in the clearance of pathogens from the host (Lindgren et al., 1996). In IFN$\gamma$-activated RAW264.7 macrophages we sought to determine the effect of Salmonella Typhimurium infection on the nitrite response. Treatment of RAW264.7 macrophages with IFN- $\gamma$ led to an increased production of nitrite (a measure of NO synthesis) in the culture supernatant. However, when the IFN- $\gamma$-treated cells had been infected with the WT Salmonella at an m.o.i. of 150, 100, 10 or 1 for $12 \mathrm{~h}$, a striking reduction in the nitrite production was observed in the culture supernatants (Fig. 1a). This difference was seen even when the cells were pretreated with IFN- $\gamma$ for $12 \mathrm{~h}$ before performing the infection (Fig. 1b). The phenomenon was abolished at very low m.o.i., suggesting the fact it might be dependent on a bacterial protein. No decrease in cell number or viability was observed in any of the experimental conditions as 
(a)

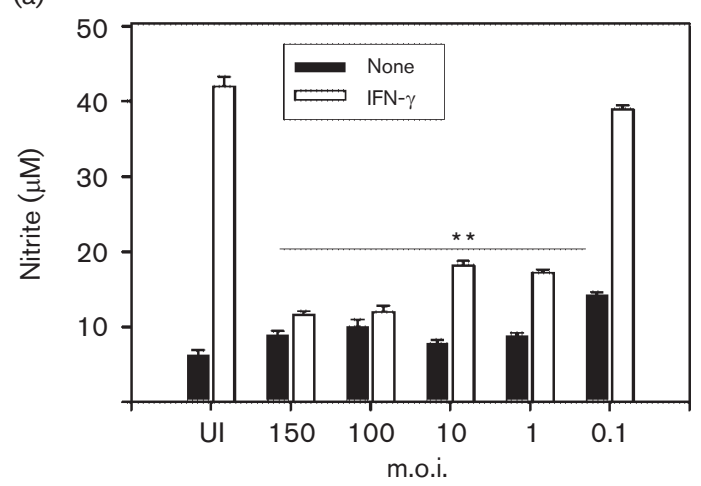

(c)

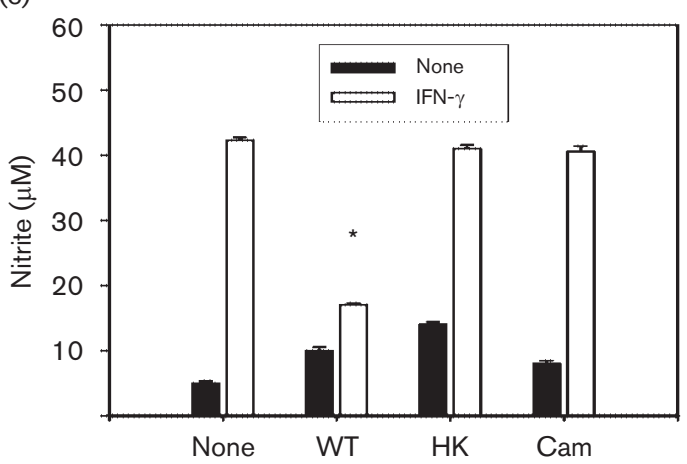

(b)

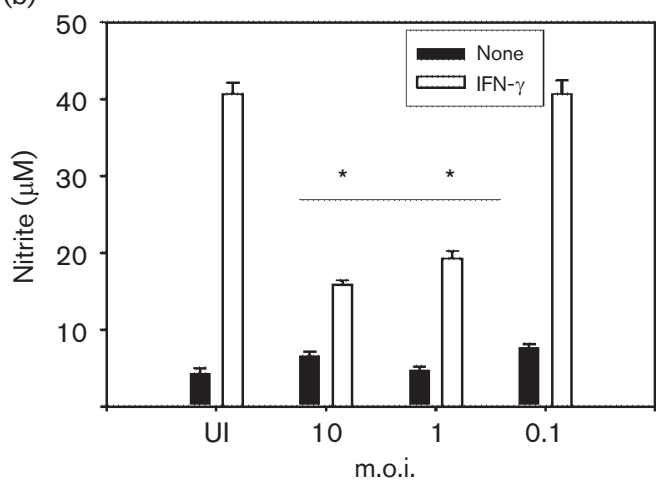

(d)

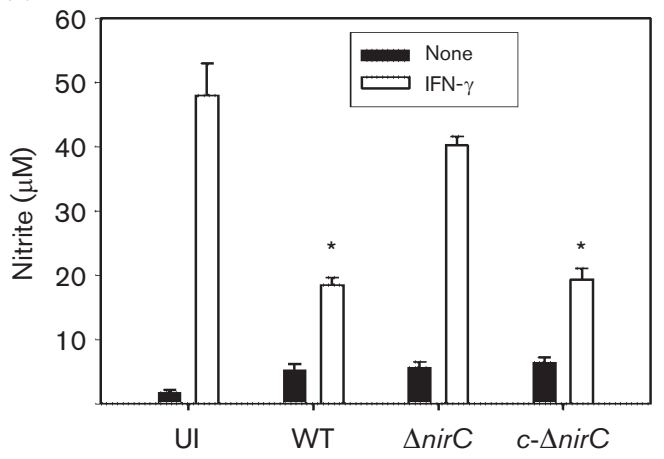

Fig. 1. $(\mathrm{a}-\mathrm{c})$ Nitrite production is suppressed in IFN- $\gamma$-activated RAW264.7 macrophages by WT Salmonella Typhimurium. (a) RAW264.7 cells were infected for $12 \mathrm{~h}$ with WT Salmonella at various m.o.i., with or without simultaneous IFN- $\gamma$ treatment. (b). RAW264.7 cells were pretreated with IFN- $\gamma$ for $12 \mathrm{~h}$ and then infected for $12 \mathrm{~h}$ with WT Salmonella at various m.o.i. (c) RAW264.7 cells were infected at an m.o.i. of 10, in the presence or absence of IFN- $\gamma$, with heat-killed WT Salmonella (HK), and with live WT bacteria with or without chloramphenicol (Cam; $15 \mu \mathrm{g} \mathrm{ml}^{-1}$ ) treatment. Production of nitrite was determined in culture supernatants by Griess reaction. Values are expressed as mean \pm SD of one of three independent experiments performed in triplicate. (d) NO production is suppressed in IFN- $\gamma$-activated RAW264.7 macrophages by WT Salmonella in a $\Delta$ nirCdependent manner. RAW264.7 cells were infected at an m.o.i. of 10 with WT Salmonella, nirC mutant and the nirCcomplemented strain (c- $\Delta$ nirC). Production of nitrite was determined in culture supernatants by Griess reaction. Statistical significance was defined as follows: ${ }^{*}, P<0.05 ;{ }^{*}, P<0.01$ (Student's $t$ test). UI, uninfected. The concentration of IFN- $\gamma$ was $100 \mathrm{IU} \mathrm{ml}^{-1}$ in each case.

indicated by MTT (tetrazolium) assay (Supplementary Fig. S2). We carried out all subsequent experiments with an m.o.i. of 10 and IFN $-\gamma$ was added at 25 min after infection to mimic the in vivo infection system, wherein cytokines are produced after bacterial infection. Heat-killed Salmonella did not show the response seen with viable bacteria. We also observed that WT-induced downregulation of nitrite was abrogated by chloramphenicol treatment to inhibit prokaryotic protein synthesis (Fig. 1c).

We hypothesized that the nitrite transporter NirC might modulate the host NO response in favour of the pathogen. Therefore, we analysed the nitrite production by the nirC mutant. As shown in Fig. 1(d), the nirC mutant showed a heightened $\mathrm{NO}$ response upon IFN- $\gamma$ treatment when compared to the WT bacteria. The nirC-complemented strain displayed inhibition of IFN- $\gamma$-induced NO production similar to the WT bacteria. Hence, $\Delta$ nirC Salmonella has lost its ability to downregulate the IFN- $\gamma$-induced nitrite production.

\section{Regulation of the nirC promoter}

An assay system to mimic the RNS stress is acidified nitrite (Kim et al., 2003). Therefore, the influence of nitrite stress on the expression of the nirC promoter was examined using acidified $\mathrm{NaNO}_{2}$. The $\beta$-galactosidase activity of the nirC: : lacZ promoter construct was measured. As shown in Fig. 2(a) the promoter activity was increased up to twofold after $3 \mathrm{~h}$ stress with $500 \mu \mathrm{M} \mathrm{NaNO}{ }_{2}$ exposure (acidic and normal $\mathrm{pH}$ ). Anaerobic incubation also led to a similar increase in the promoter activity. The promoterless construct (empty vector) showed negligible $\beta$-galactosidase activity under all conditions tested. Hence, for the empty vector the $\beta$-galactosidase activity is shown for only one 
representative condition. When oxidative stress was conferred by adding $500 \mu \mathrm{M} \mathrm{H} \mathrm{H}_{2} \mathrm{O}_{2}$, no change was observed in the transcription of the nirC promoter construct, suggesting high specificity of this transporter for nitrite (Fig. 2a). In infected RAW264.7 cells, IFN- $\gamma$ induction led to a threefold increase in the nirC promoter activity (Fig. 2b).

\section{nirC-deficient Salmonella Typhimurium is unable to transport nitrite}

It has been reported that in E. coli, deletion of the nirC gene decreased nitrite uptake (Clegg et al., 2002). Hence, the rate of nitrite uptake by the nirC mutant and WT bacteria cultured in minimal medium was assessed. Strikingly, when nitrite consumption from an initial concentration of $75 \mu \mathrm{M}$ was measured, the WT bacteria rapidly consumed nitrite whereas in the $\Delta$ nirC Salmonella the consumption was significantly less, demonstrating that $\mathrm{NirC}$ is responsible for nitrite uptake in Salmonella under this aerobic experimental condition. The rate of consumption of nitrite in the complemented strain was comparable to that of the WT (Fig. 2c).

\section{nirC-deficient Salmonella is attenuated in activated macrophages}

The growth of the WT and $\Delta$ nirC strains was comparable in both LB and pH 7 minimal medium (data not shown). The role of the nirC gene in intracellular survival in RAW264.7 macrophages was then investigated. As shown in Fig. 3(a), there was an almost 12-fold increase in the WT from 2 to $16 \mathrm{~h}$ in the absence of IFN $-\gamma$ treatment, whereas with IFN- $\gamma$ treatment it was 3.5 -fold. The $\Delta$ nirC strain under similar conditions was attenuated in the macrophages: it showed a 6-fold increase from 2 to $16 \mathrm{~h}$ in the absence of IFN- $\gamma$, and no replication in the presence of IFN $-\gamma$. In the case of infection with the complemented strain the growth was similar to that of the WT. Similar results were observed in BMDM: the $\operatorname{nirC}$ strain was significantly attenuated in the presence of IFN- $\gamma$ (Fig. 3b). This attenuation was abrogated when the survival assay was performed in the presence of the iNOS inhibitor LNIL. In order to better understand whether inability to use nitrite could lead to this attenuation, we further checked the survival of a $\triangle$ nirBD strain (a kind gift of Professor Michael Hensel), in which nitrite transport is normal. The data presented in Supplementary Fig. S3 indicate that the reductase knockout strain grew just as well as the WT strain. Furthermore, the NO response as determined by Griess assay was also similar to that of the WT strain (data not shown). Hence, it can be inferred that the inability to transport nitrite in the $\Delta$ nirC strain is responsible for the observed attenuation. Thus, the transport of nitrite is the essential step, not the reduction per se.
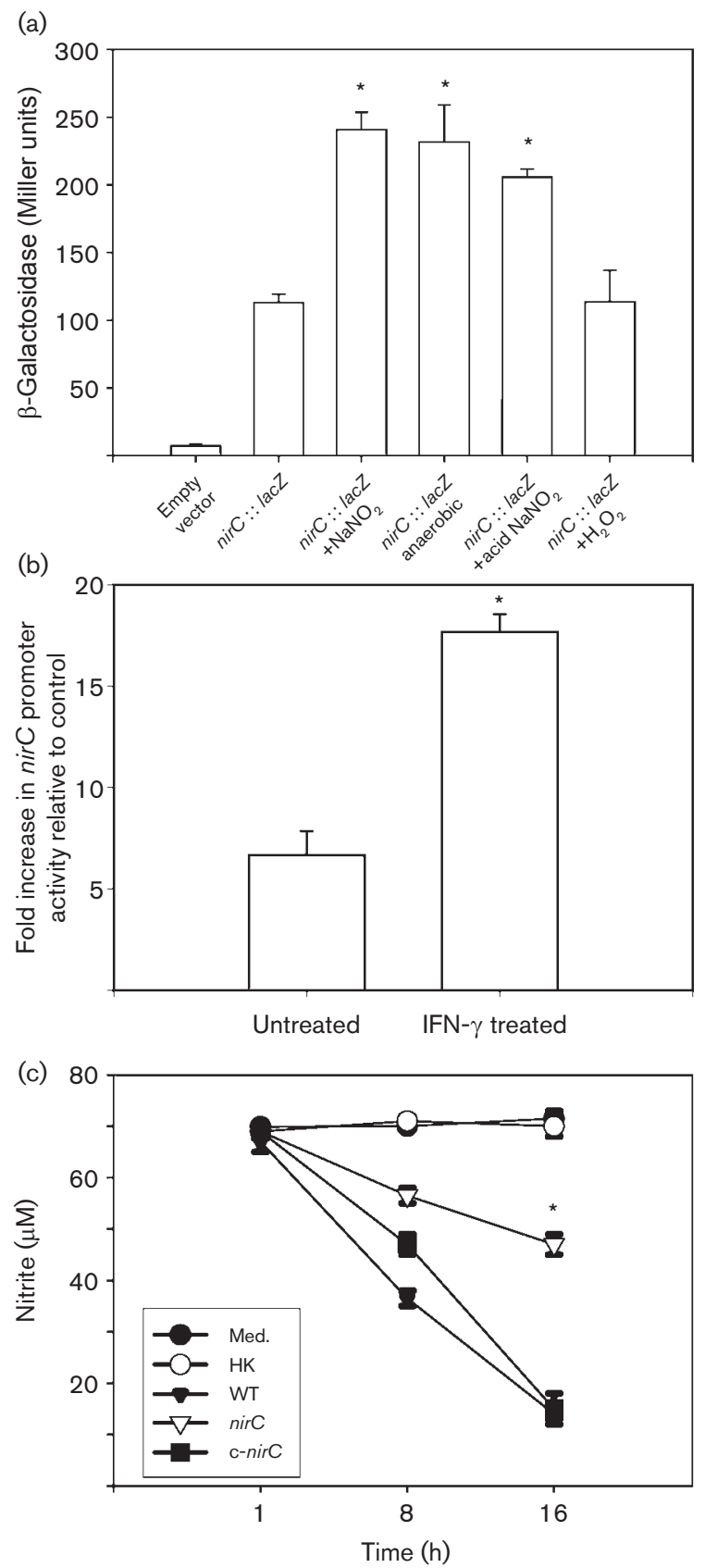

Fig. 2. $\mathrm{NaNO}_{2}$ stress and anaerobic growth upregulate the expression of the nirC gene. (a) nirC transcription was quantified by measuring $\beta$-galactosidase activity of the strain expressing a nirC: : lacZ promoter construct. The bacteria were grown in lowosmolarity $\mathrm{M}$ salts medium with or without the presence of the nitrite donor $\mathrm{NaNO}_{2}$, or $\mathrm{H}_{2} \mathrm{O}_{2}$, or under anaerobic conditions; promoter activity was measured in Miller units after $3 \mathrm{~h}$ of stress. (b) RAW264.7 cells were infected with the WT strain expressing a nirC : : lac Z promoter construct, with or without IFN- $\gamma$ treatment. At $12 \mathrm{~h}$ post-infection cell lysates were collected and $\beta$-galactosidase activity was determined. (c) WT, nirC mutant and complemented $\triangle$ nirC strains were cultured in defined glucose medium buffered with MOPS ( $\mathrm{pH}$ 8.0). Nitrite uptake was measured as described in Methods. Statistical significance was defined as follows: * $P<0.05$ (Student's $t$ test). 

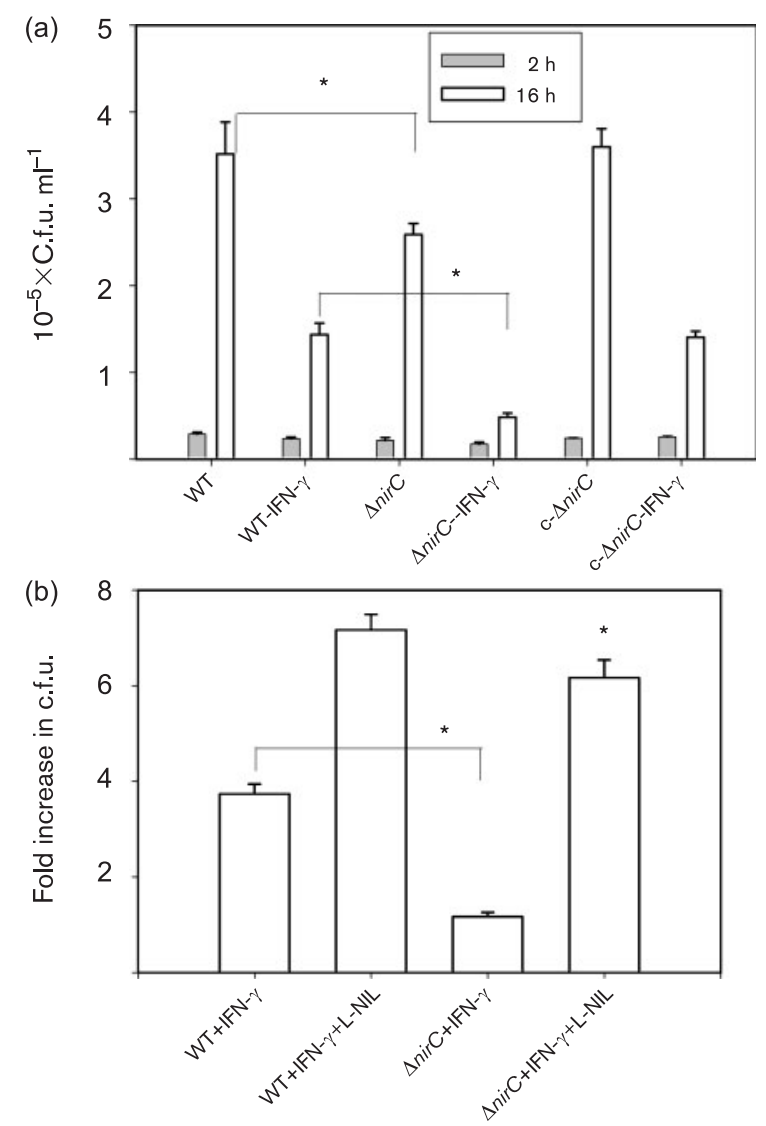

Fig. 3. Intracellular survival assays. (a) RAW264.7 macrophages both with and without IFN- $\gamma$ stimulation were infected with WT or $\Delta$ nirC bacteria at an m.o.i. of 10 . Infected macrophages were lysed at 2 and $16 \mathrm{~h}$ post-infection and the bacterial loads were determined in triplicate. (b) Fold increase in c.f.u. in BMDM between $2 \mathrm{~h}$ and $16 \mathrm{~h}$ after infection (data from three independent experiments). The WT- or $\Delta$ nirC-infected cells (m.o.i. 10) were treated with IFN- $\gamma$ only or with IFN- $\gamma$ plus L-NIL. Statistical significance was defined as follows: ${ }^{*}, P<0.05$ (Student's $t$ test).

\section{Increased formation of peroxynitrite is observed in IFN- $\gamma$-treated macrophages when infected with $\Delta$ nirC as compared to WT Salmonella Typhimurium}

In order to understand the precise effect of the high NO in the $\Delta$ nirC Salmonella-infected macrophages in response to IFN- $\gamma$, we looked at the formation of peroxynitrite. The most potent bactericidal effect of $\mathrm{NO}$ appears to be via reaction with $\mathrm{O}_{2}^{-}$leading to the formation of the highly toxic peroxynitrite $\left(\mathrm{OONO}^{-}\right)$, which can kill Salmonella (De Groote et al., 1995). Peroxynitrite generated in the cells cannot be detected directly, but sites of damage due to the reaction of peroxynitrite can be assessed by the immunohistochemical staining of nitrotyrosine. The results presented in Fig. 4 indicate that in activated macrophages infected with WT Salmonella, the level of nitrotyrosine residues was low and showed little colocalization with the bacteria. But in the case of $\Delta$ nirC infection there was enhanced peroxynitrite formation and increased colocalization with the bacteria. When aminoguanidine was used to inhibit the formation of RNS, there was no staining of peroxynitrite, indicating the specificity of the antibody (Fig. 4). To check the amount of ROS produced, extracellular $\mathrm{H}_{2} \mathrm{O}_{2}$ production was compared in the macrophages. There was no significant difference in the $\mathrm{H}_{2} \mathrm{O}_{2}$ production (data not shown).

\section{Downregulation of IFN- $\gamma$-induced NO synthesis due to nirC-dependent reduction in iNOS expression}

To further examine the correlation between NO production and iNOS expression, we looked at the translational levels of iNOS in infected and uninfected cells with IFN $-\gamma$ treatment. Expression of iNOS protein was quantified by Western blot analysis (Fig. 5a). IFN- $\gamma$-stimulated macrophages showed increased iNOS expression compared to the control cells, accompanied by a fivefold increase in nitrite level. Cells that were infected with WT Salmonella along with IFN- $\gamma$ treatment showed a marked reduction in the iNOS protein levels, which were also reflected in the nitrite production in the culture supernatant as compared to IFN$\gamma$-stimulated macrophages alone. In contrast, the expression of iNOS protein was not downregulated following infection with $\Delta$ nirC Salmonella. Upon IFN $-\gamma$ treatment in the RAW264.7 cells the relative intensity of iNOS protein was $60 \%$. However, upon WT infection the IFN- $\gamma$-treated macrophages exhibited only $30 \%$ relative intensity for iNOS, whereas in the case of macrophages infected with the $\Delta$ nirC Salmonella it was around $55 \%$ (Fig. 5b). We obtained similar results in flow cytometric analysis of iNOS protein (data not shown). Taken together, these results clearly indicate that the reduction in IFN- $\gamma$-induced iNOS expression seen in RAW264.7 macrophages infected with WT Salmonella does not occur in a nirC mutant background.

\section{The IFN- $\gamma$-induced high NO response in $\Delta$ nirC Salmonella-infected macrophages is due to nirC- dependent increase in STAT-1 phosphorylation}

Subsequent studies focused on the signal transduction pathways that govern IFN- $\gamma$-induced NO synthesis. As phosphorylation of STAT-1 is a crucial downstream signalling event of the IFN- $\gamma$ pathway (Boehm et al., 1997), experiments were conducted to check the amount of P-STAT-1 in infected cell lysates. The $\Delta$ nirC strain allowed a higher level of STAT-1 phosphorylation in the activated macrophages than did the WT bacteria. The level of PSTAT- 1 at $8 \mathrm{~h}$ post-infection in the WT-infected and IFN$\gamma$-activated macrophages was more than twofold lower than in those infected with the nirC mutant (Fig. 5c). These results indicate that the high NO output in the $\Delta$ nirCinfected macrophages arises due to the increased phosphorylation of STAT-1. 

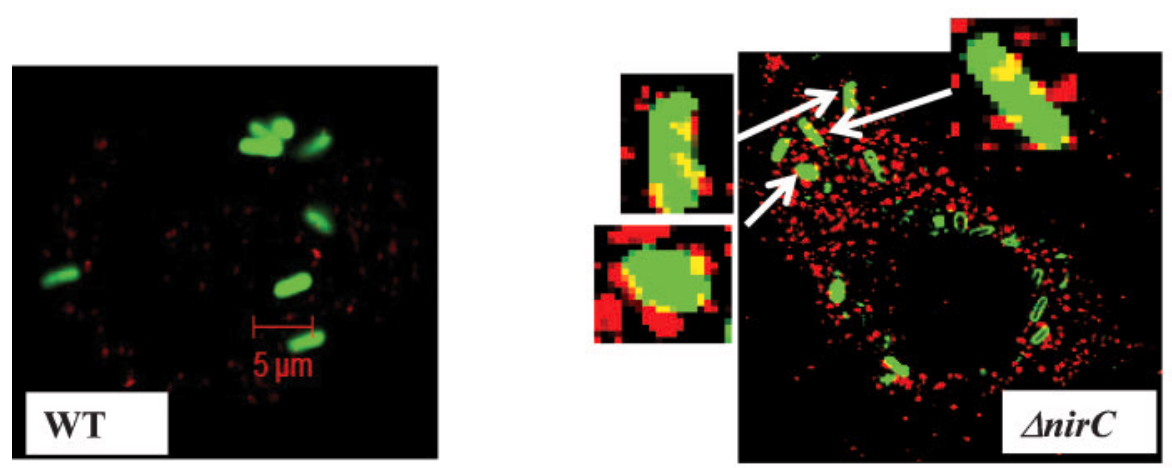

\section{Aminoguanidine}

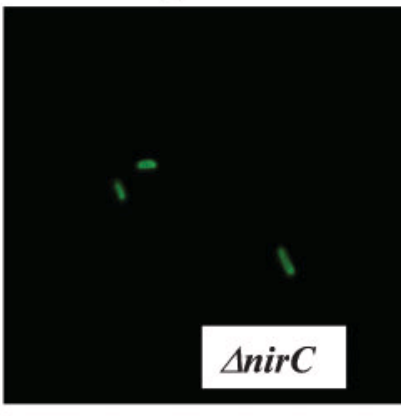

Salmonella

Nitrotyrosine

Fig. 4. (a) nirC mutant Salmonella Typhimurium shows enhanced peroxynitrite formation. The sites of peroxynitrite formation were detected by immunostaining with an anti-nitrotyrosine antibody and a Cy5-conjugated secondary antibody. Samples were analysed by confocal laser-scanning microscopy; representative images for the localization of the bacterial cells (green) and nitrotyrosine residues (red) are shown. A control experiment with aminoguanidine is shown on the far right.

(a)

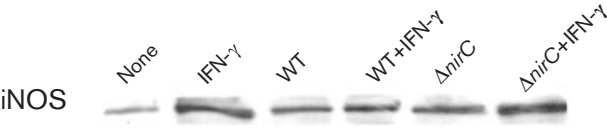

P-STAT-1

$\beta-$ Actin

(b)

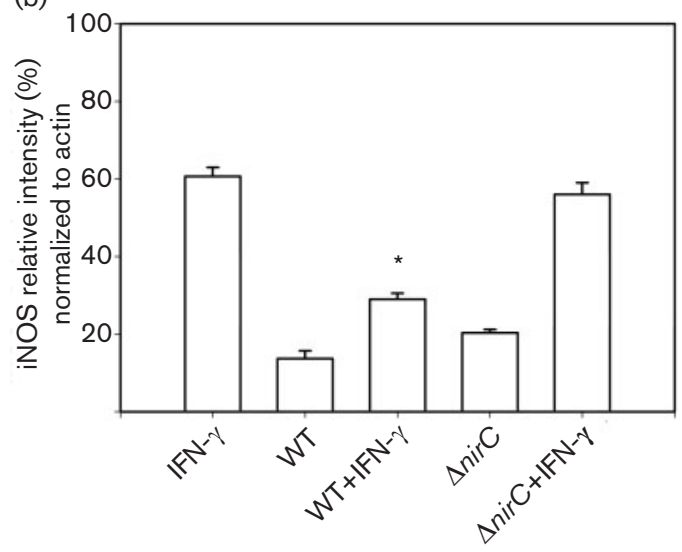

(c)

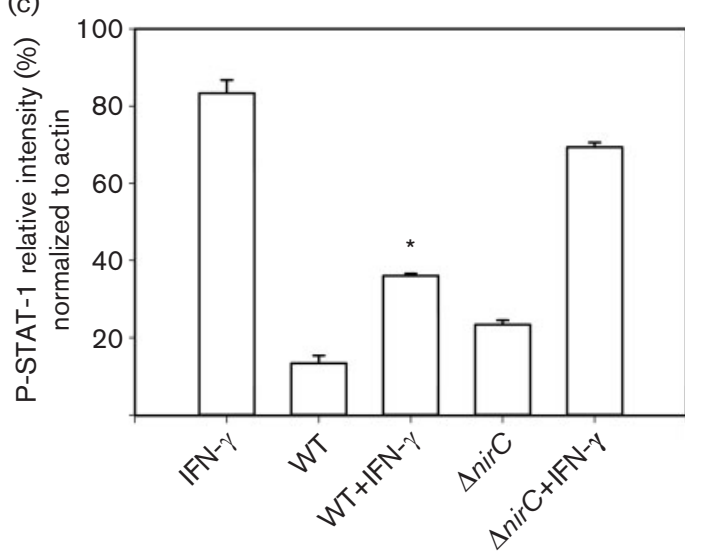

Fig. 5. Live Salmonella Typhimurium infection downregulates STAT-1 phosphorylation and iNOS protein expression in activated RAW264.7 macrophages in a nirC-dependent manner. RAW264.7 cells were infected with either the WT or nirC mutant Salmonella for $8 \mathrm{~h}$. Then total protein was extracted from the cells and a $100 \mu \mathrm{g}$ sample was subjected to Western blot analysis to check the levels of iNOS level (a, upper panel) and phosphorylated STAT-1 (a, middle panel) (b). Relative intensities of the iNOS (b) and P-STAT (c) blots obtained by densitometric image analysis in which the density values of the test proteins were normalized to those of $\beta$-actin and plotted as means of three independent experiments. Statistical significance was defined as follows: * $P<0.05$ (Student's $t$ test). 


\section{NO inhibits the expression of spiC in a nirC- dependent manner}

Consistent with previous findings (McCollister et al., 2005), we also observed the NO-mediated suppression of spiC promoter activity by $\beta$-galactosidase assay in the WT Salmonella. However, the downregulation of spiC under acidified nitrite conditions when compared to a no-stress control was much more pronounced in the $\Delta$ nirC Salmonella: $500 \mu \mathrm{M} \quad \mathrm{NaNO}_{2}$ under acidic conditions reduced spiC transcription by 80 -fold in the $\Delta$ nirC strain but only 45 -fold in case of the WT strain (Fig. 6a). spiC transcription was also checked independently by RT-PCR. As shown in Fig. 6(b, c), in accordance with $\beta$-galactosidase activity, PCR amplification revealed more reduction in spiC transcription in the $\Delta$ nirC strain than in the WT after $3 \mathrm{~h}$ of growth in the SPI2-inducing low-osmolarity $\mathrm{N}$ salts medium. In contrast, the expression of the housekeeping gene encoding 16S rRNA was similar after $3 \mathrm{~h}$ of culture and was not affected by the addition of $\mathrm{NaNO}_{2}$.

\section{Supplying spiC in trans abrogates the nirC- dependent enhanced nitrite production}

Our previous results suggested that in the $\Delta$ nirC strain, the amount of spiC was significantly less than in the WT under acidified nitrite stress. To check the relevance of this finding in the cell culture model, we infected RAW264.7 cells with either the WT or the $\Delta$ nirC strain, each harbouring the spiC promoter cloned in a promoterless plasmid. It was found that in the presence of IFN- $\gamma$ the level of spiC was significantly downregulated in both the strains. However, the spiC promoter activity was significantly lower in the $\triangle$ nirC strain than in the WT in the activated macrophage population (Fig. 7a).

spiC cloned strains were further evaluated for their nitrite production in BMDM. The WT strain with the spiC clone produced a significantly lower amount of nitrite in the activated cell supernatant when compared to the WT control. Similar results were obtained in the case of the $\Delta$ nirC strain. The enhanced nitrite production by the $\Delta$ nirC strain when compared to cells treated with only IFN $-\gamma$ was abrogated in the $\Delta$ nirC/pQE60-spiC ${ }^{+}$strain (Fig. 7b).

The intracellular growth in activated BMDM was also in accordance with the nitrite values (Fig. 7c). Interestingly, the attenuation of the $\Delta$ nirC strain was completely reverted in the $\Delta$ nirC/pQE60-spiC ${ }^{+}$strain. These data clearly indicate that the decreased spiC level actually leads to the enhanced nitrite production and growth retardation in the $\Delta$ nirC strain.

\section{Lower burden of the $\Delta$ nirC strain in the organs of mice}

It has been reported previously that Salmonella infection upregulates IFN- $\gamma$ production in mice lymphoid tissues and spleen (Ramarathinam et al., 1991). As our previous (a)
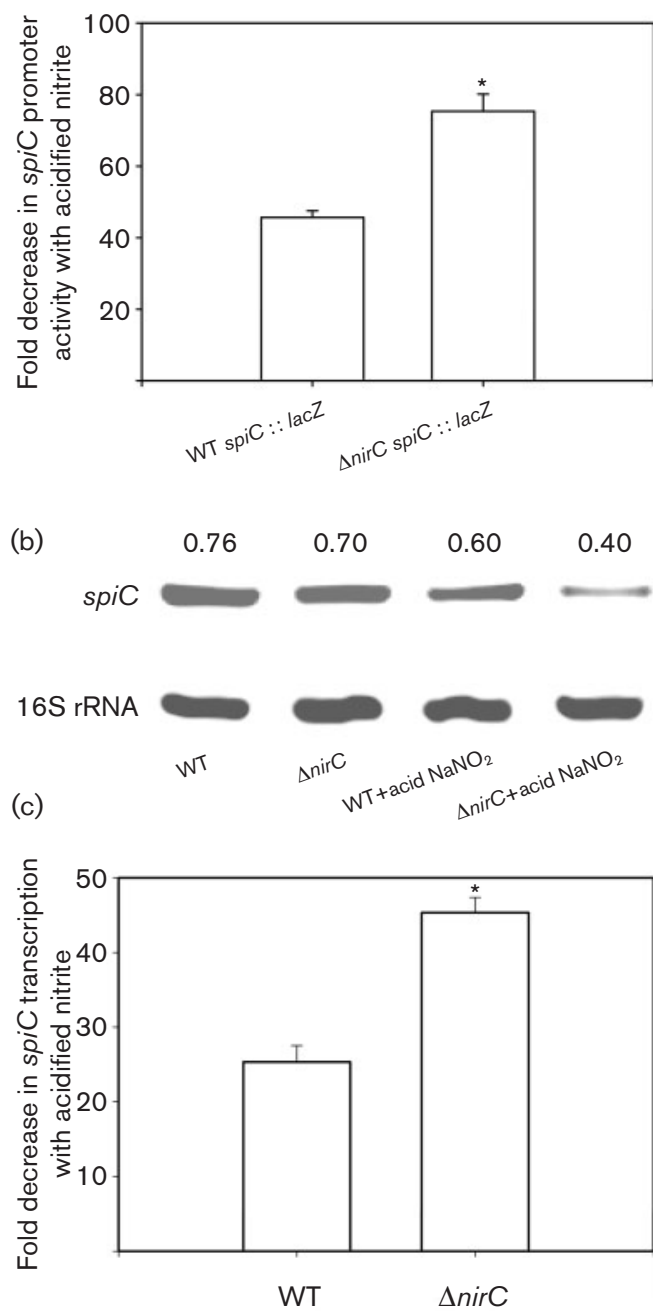

Fig. 6. Increased inhibition of SPI2 transcription in nirC mutant Salmonella by NO. (a) SPI2 was quantified by measuring $\beta$ galactosidase activity of the strain expressing a spiC::lac $Z$ promoter construct. The bacteria were grown in low-osmolarity $\mathrm{N}$ salts medium in the presence of the nitrite donor acidified $\mathrm{NaNO}_{2}$. (b) Transcription of spiC and 16S rRNA genes was quantified by RT-PCR amplification of RNA samples isolated from the WT and $\Delta$ nirC strains cultured in $8 \mu \mathrm{M} \mathrm{MgCl}_{2} \mathrm{~N}$ salts medium in the presence or absence of $500 \mu \mathrm{M}$ acidified $\mathrm{NaNO}_{2}$. The abundance of spiC transcript relative to internal $16 \mathrm{~S}$ rRNA levels, determined by densitometric analysis, is shown above the respective lanes. (c) Mean fold decrease in spiC transcription from three independent experiments detemined by densitometric analysis and normalization with $16 \mathrm{~S}$ rRNA.

results suggested increased susceptibility of the $\Delta$ nirC strain in IFN- $\gamma$-activated macrophages, we next sought to correlate our findings in the mouse model of infection. We infected groups of 10 mice with WT or $\Delta$ nirC bacteria. As shown in Fig. 8(a), the bacterial burden in spleens of $\Delta$ nirC-infected mice after 5 days of infection was signific- 

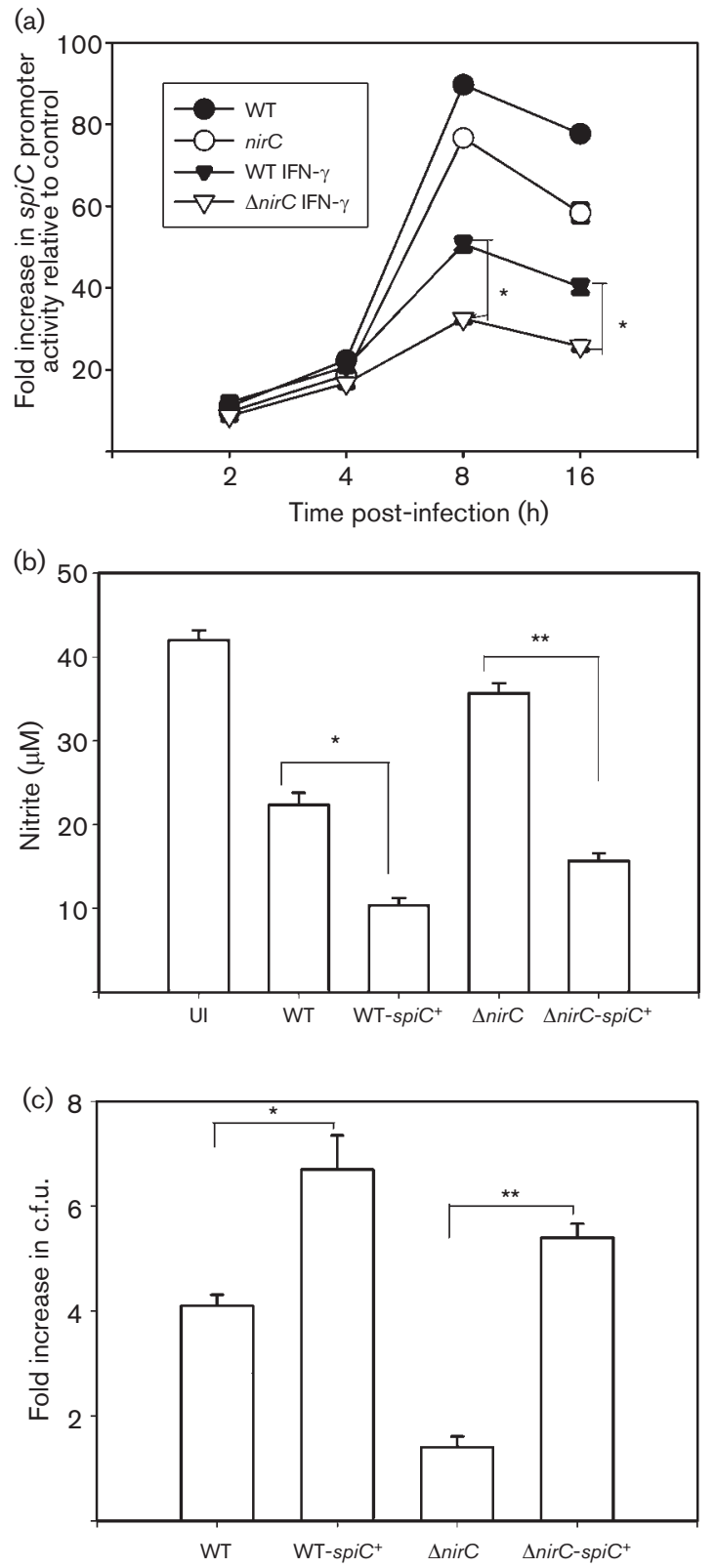

Fig. 7. (a) Analysis of promoter activity of spiC. RAW264.7 cells were infected at an m.o.i. of 10 with WT and nirC mutant Salmonella carrying spiC: lacZ promoter construct or with WT Salmonella carrying empty vector, with or without IFN- $\gamma$. At selected time points post-infection cell lysates were collected and $\beta$-galactosidase activity was determined. (b, c) Nitrite production and growth in BMDM. (b) BMDM were infected at an m.o.i. of 10 with WT Salmonella, with the nirC mutant or with each strain carrying the $s p i C^{+}$plasmid pQE60. IFN- $\gamma$ was added the time of infection. Production of nitrite was determined in culture supernatants by Griess reaction after $12 \mathrm{~h}$ of infection. Values are expressed as mean \pm SD of one of three independent experiments performed in triplicate. UI, uninfected. (c) BMDM were infected as in (b). IFN- $\gamma$ was added at the time of infection. The fold increase in c.f.u. in BMDM between $2 \mathrm{~h}$ and $16 \mathrm{~h}$ from three independent experiments is plotted. Statistical significance was defined as follows: *,$P<0.05$; ${ }^{*}, P<0.01$ (Student's $t$ test).

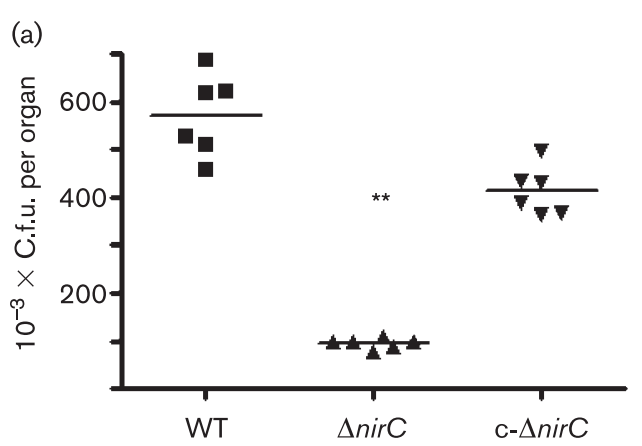

(b)

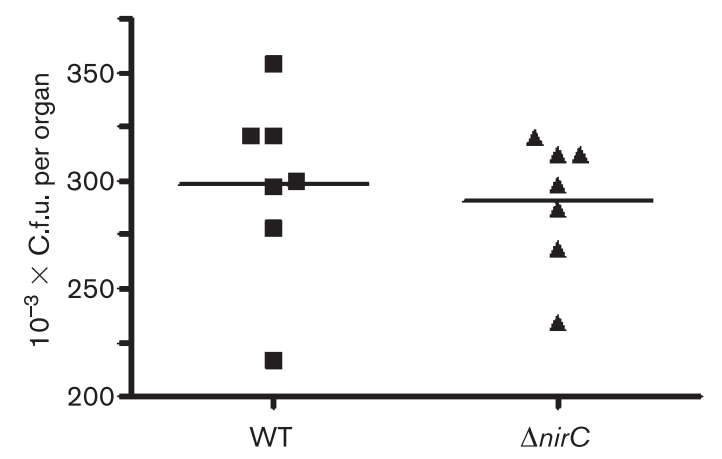

(c)

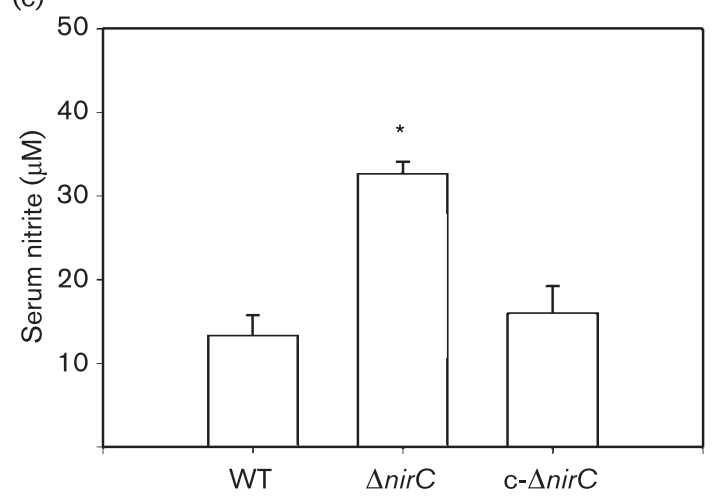

Fig. 8. (a, b) $\Delta$ nirC Salmonella is attenuated for virulence in $\mathrm{BALB} / \mathrm{c}$ mice and proliferates like the WT strain in various organs of congenic iNOS $^{-1-}$ mice. After 5 days of infection, homogenized samples of spleens from BALB/c mice (a) and $\mathrm{iNOS}^{-1-}$ mice (b) were plated on antibiotic plates and the colonies were counted. The results presented are from one of three independent experiments. (c) Serum nitrite from BALB/c mice infected with the WT, $\Delta$ nirC or complemented $\Delta$ nirC strain (three mice per group) was measured as described in Methods. Statistical significance was defined as follows: *, $P<0.05,{ }^{* *} ; P<0.01$ (Mann-Whitney $U$ test).

antly less than that in the WT-infected mice. The complemented strain (c- $\Delta$ nirC) showed significant reversion from the mutant strain in in vivo growth. Production of serum nitrite was further compared between the infected mice groups. In accordance with our cell culture data, we 
also observed an increased production of nitrite in the serum of the $\Delta$ nirC-infected mice (Fig. $8 \mathrm{c}$ ).

Further, competitive index assay in $\mathrm{BALB} / \mathrm{c}$ mice (Supplementary Table S3) showed that the $\Delta$ nirC strain exhibited a virulence defect. The WT strain outcompeted the $\Delta$ nir $C$ strain in all the organs analysed (liver, spleen and MLN) in mixed-infected mice. The complemented $\Delta$ nirC strain was found to compete equally against the WT strain.

\section{In iNOS ${ }^{-/-}$mice the $\Delta$ nirC strain grows just as well as the WT strain}

In order to confirm our findings, we next challenged congenic $\mathrm{iNOS}^{-1-}$ mice orally with either the WT or the knockout bacteria. After 5 days of infection, the load of the $\triangle$ nirC strain from all the organs examined was similar to that of the WT bacteria. As shown in Fig. 8(b), there was no significant difference in the bacterial burden after 5 days of infection in the spleens of $\Delta$ nirC-infected $\mathrm{iNOS}^{-/-}$mice versus WT-infected iNOS ${ }^{-1-}$ mice.

\section{DISCUSSION}

Survival of Salmonella Typhimurium inside macrophages depends on the ability of the bacteria to evade various host defence mechanisms (Fields et al., 1986). We have shown that IFN- $\gamma$-treated RAW264.7 cells infected with WT Salmonella showed inhibition of iNOS induction and NO production. Inhibition of NO production as a survival strategy is used by various other pathogens such as Cryptococcus neoformans (Kawakami et al., 1997), Trypanosoma cruzi (Pakianathan \& Kuhn, 1994) and Leishmania major (Balestieri et al., 2002; Proudfoot et al., 1995, 1996). Interferons are pro-inflammatory cytokines involved in both innate and acquired immune responses and are known to enhance iNOS expression by macrophages (Boehm et al., 1997; MacMicking et al., 1997; Rottenberg et al., 2000). In addition, several lines of evidence have shown that many pathogenic bacteria are rapidly killed by interferon-activated macrophages by various means (Miyagi et al., 1997; Nairz et al., 2008). We observed that infection with live bacteria is required for the manifestation of the NO inhibition phenotype, as heatkilled Salmonella was unable to inhibit NO synthesis. The inhibition of IFN- $\gamma$ stimulated NO production was also found to be dependent on the m.o.i. used. No inhibition was observed in the macrophages infected with an m.o.i. of less than 1. Prokaryotic protein synthesis was required for the manifestation of this phenotype, as it was not seen in the presence of chloramphenicol.

This work further elucidates the role of NirC protein in Salmonella virulence. Our bioinformatics study predicted that NirC of Salmonella indeed is a polytopic membrane protein similar to its E. coli homologue, having six transmembrane helices. The high homology of this protein amongst various Salmonella serovars and many other known nitrite transporters from diverse bacterial species also confirms the role of $\mathrm{NirC}$ in nitrite transport. Various transcriptional regulators and enzymes that detoxify $\mathrm{NO}$ in many diverse micro-organisms, particularly pathogenic bacteria including Salmonella, are well documented (Gilberthorpe et al., 2007; Mills et al., 2008). However, to our knowledge no study has previously addressed the role of nitrite transporters in Salmonella. The novel function of NirC is accomplished by its nitrite transporter activity as opposed to the NO-detoxifying mechanisms used by HmpA and NorV. NarK also serves as a nitrite importer but NirC can maintain nitrite uptake at the normal rate in the absence of NarK (Clegg et al., 2002). A non-polar deletion mutant of the nitrite transporter nirC in Salmonella was constructed and our data showed that a higher level of nitrite was induced in the supernatant of the nirC mutant Salmonella-infected macrophages than that of the WT-infected macrophages. Furthermore, nirC transcription was demonstrated to be upregulated in the presence of nitrite stress and under anaerobic conditions, but hydrogen peroxide stress had no effect. This suggests that the transcription of nirC is upregulated in the presence of high nitrite and it then acts as a nitrite transporter and might help the bacteria to adapt to RNS stress. Our data strongly indicate that $\mathrm{NirC}$ is the principal nitrite transporter in Salmonella, as the deficiency of NirC reduced the nitrite uptake significantly and its complementation fully restored it.

The nir $C$ mutant was attenuated in the mouse macrophage cell line RAW264.7 and in BMDM both with and without IFN- $\gamma$ activation, and in an in vivo mouse model. L-NIL treatment abrogated this attenuation, indicating that the nir C growth defect is solely due to NO stress. The reaction of RNS with ROI generates peroxynitrite (Pacher \& Szabo, 2006), a reactive molecule with potent antimicrobial activity against Salmonella Typhimurium in vitro and rarely colocalizing with WT Salmonella (Chakravortty et al., 2002). In contrast, nitrotyrosine residues were frequently located in the vicinity of as well as co-localized with the nirC mutant bacteria. Thus, in the nirC-infected cells, an increased level of RNS leads to enhanced production of peroxynitrite and might be responsible for the observed attenuation. We can speculate that the intracellular survival of Salmonella even after IFN- $\gamma$ treatment is due to our proposed mechanism of NirC-mediated NO quenching, which makes infected cells less responsive to cytokine activation. In the mouse model of infection, the knockout bacteria were attenuated when compared to the WT strain in all the organs tested. Similar results were obtained in the competitive index experiment: the WT bacteria could outcompete the knockout bacteria in a mixed infection. A previous study reported that IFN- $\gamma$ plays a crucial role in Salmonella infection (Bao et al., 2000). The increased production of serum nitrite after $\Delta$ nirC infection also leads to the same conclusion, further validating our cell culture data. However, in the iNOS ${ }^{-1-}$ mouse model of infection the attenuation of the $\Delta$ nir $C$ was abrogated. 
To arrive at a rationale for this heightened $\mathrm{NO}$ response in the nirC mutant Salmonella, we examined the iNOS expression and JAK/STAT-1 signalling pathway upon IFN- $\gamma$ stimulation. Surprisingly, the levels of P-STAT-1 and iNOS induction with IFN- $\gamma$ treatment in the $\Delta$ nirCinfected macrophages were significantly higher than that of the WT-infected macrophages. Functioning of the type III secretion system encoded by SPI2 is essential for the ability of Salmonella to cause systemic infections and for intracellular survival (Hensel, 2000; Ochman et al., 1996; Shea et al., 1996; Waterman \& Holden, 2003). Studies have indicated that SPI2 is used by intracellular Salmonella to actively modify functions of the host cells and one of the effector proteins, SpiC, is important in this regard (Uchiya et al., 1999). SpiC was found to be required for SPI2mediated secretion of many effector proteins (Yu et al., 2002). Also, the NO-mediated inhibition of SPI2 transcription in activated macrophages is well known (McCollister et al., 2005). Additionally, the SPI2 protein SpiC plays a critical role in reducing JAK/STAT signalling. SpiC blocks the phosphorylation of STAT-1 proteins by inducing SOCS-3 (Uchiya \& Nikai, 2005). Inhibition of SPI2 function by NO is critical for the anti-Salmonella activity of IFN- $\gamma$-treated macrophages (McCollister et al., 2005) and in turn SPI2 effector proteins can inhibit IFN- $\gamma$ signalling (Uchiya \& Nikai, 2005). We provide an important connecting link between these two interesting findings regarding IFN- $\gamma$ and Salmonella biology. When spiC was cloned in trans in a low-copy-number plasmid, the nirC-dependent high nitrite production and attenuation was abrogated in the knockout strain.

A model for the protective role of NirC based on our results is shown in Fig. 9. In this model, transporting nitrite inside the bacteria reduces the amount of toxic NO. As a result, the SPI2 inhibition by NO is significantly decreased. It has been reported that $\mathrm{NO}$ can be auto-oxidized to nitrite (Kharitonov et al., 1994). Nitrite, which is not freely diffusible like NO, cannot be transported inside the bacteria in the nirC mutant strain. Hence, it can be speculated that the increased amount of nitrite surrounding the Salmonella-containing vacuole or individual bacteria in the acidic condition might be reconverted to the freely diffusible NO and upon entering the bacteria can suppress SpiC expression. Our study has shown that in activated macrophages, the amount of SpiC repression is much more pronounced in the NirC knockout bacteria than in the WT counterpart. This reduced level of SpiC in the NirC-null background thereby cannot effectively block IFN- $\gamma$ signalling, unlike in the WT strain (Fig. 9). The upregulation of iNOS expression occurs due to enhanced phosphorylation of STAT-1 leading to an increase in NO production in the knockout strain. The ability of a nitrite
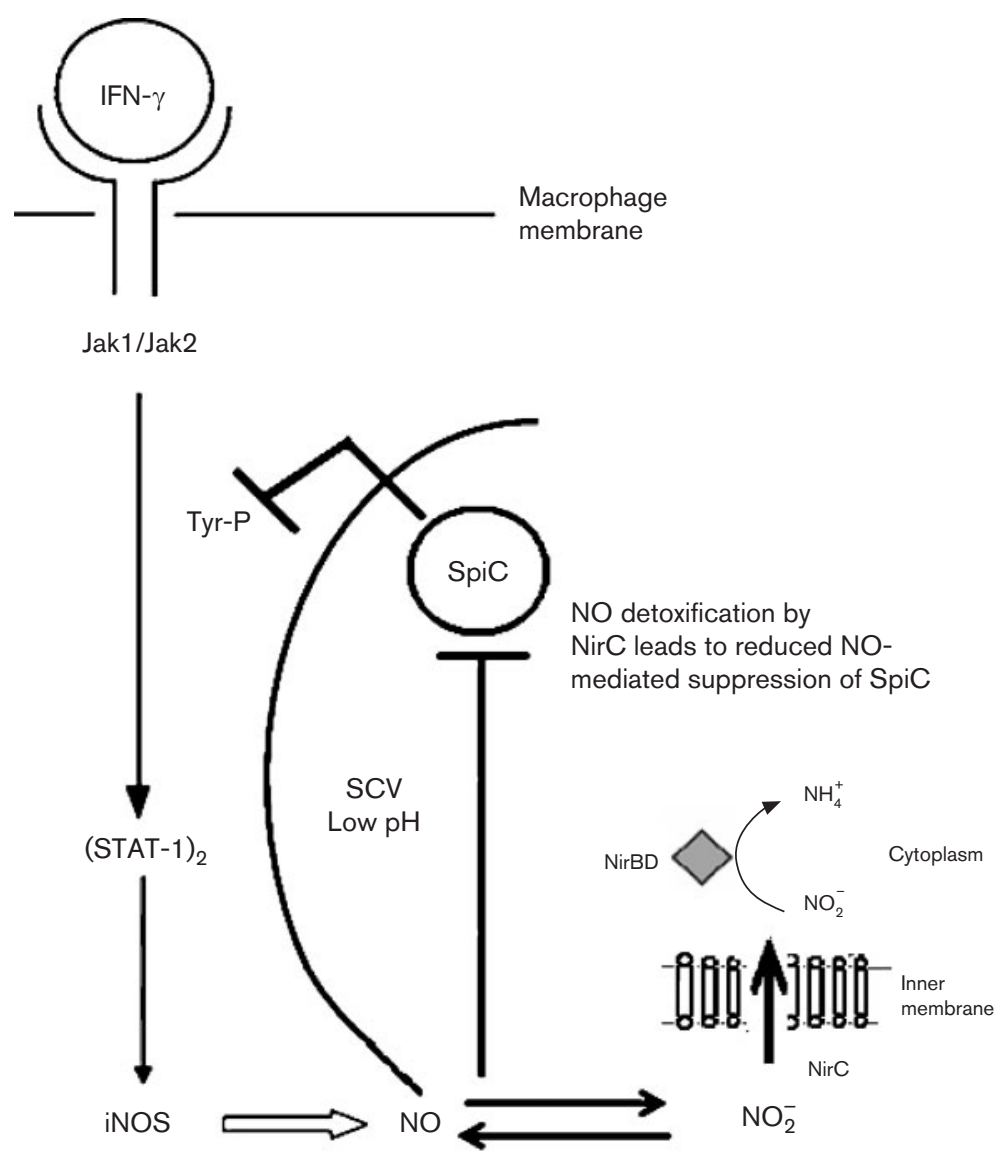

Fig. 9. Schematic summary of the NirCmediated NO quenching and SPI2-dependent iNOS inhibition. Left: IFN- $\gamma$-induced iNOS induction and NO production. Centre: NOmediated inhibition of SpiC and SpiCmediated inhibition of STAT-1 phosphorylation. Right: nitrite produced is transported into the bacteria via NirC and detoxified, resulting in a reduced amount of NO to suppress SpiC. For details, see the text. 
transporter to play a pivotal role in Salmonella pathogenesis as shown in our study represents an exciting area for future research.

\section{ACKNOWLEDGEMENTS}

We thank Professor Michael Hensel and Dr K. N. Balaji for stimulating discussions. We would also like to thank Dr Omana Joy for helping us with the FACS analysis and Sneha for the confocal studies. Sudhagar is highly acknowledged for the bioinformatics studies. We would also like to thank the Central Animal Facility (CAF) for providing the knockout mice. This work was supported by the grant Provision (2A) Tenth Plan (191/MCB) from the Director of Indian Institute of Science, Bangalore, India, and Department of Biotechnology (DBT 197 and DBT 172) to D. C. P.D. acknowledges the CSIR for a fellowship.

\section{REFERENCES}

Balestieri, F. M., Queiroz, A. R., Scavone, C., Costa, V. M., BarralNetto, M. \& Abrahamsohn Ide, A. (2002). Leishmania (L.) amazonensis-induced inhibition of nitric oxide synthesis in host macrophages. Microbes Infect 4, 23-29.

Bang, I. S., Liu, L., Vazquez-Torres, A., Crouch, M. L., Stamler, J. S. \& Fang, F. C. (2006). Maintenance of nitric oxide and redox homeostasis by the Salmonella flavohemoglobin Hmp. J Biol Chem 281, 28039-28047.

Bao, S., Beagley, K. W., France, M. P., Shen, J. \& Husband, A. J. (2000). Interferon-gamma plays a critical role in intestinal immunity against Salmonella typhimurium infection. Immunology 99, 464-472.

Beuzon, C. R. \& Holden, D. W. (2001). Use of mixed infections with Salmonella strains to study virulence genes and their interactions in vivo. Microbes Infect 3, 1345-1352.

Boehm, U., Klamp, T., Groot, M. \& Howard, J. C. (1997). Cellular responses to interferon-gamma. Annu Rev Immunol 15, 749-795.

Brett, P. J., Burtnick, M. N., Su, H., Nair, V. \& Gherardini, F. C. (2008). iNOS activity is critical for the clearance of Burkholderia mallei from infected RAW 264.7 murine macrophages. Cell Microbiol 10, 487-498.

Chakravortty, D. \& Hensel, M. (2003). Inducible nitric oxide synthase and control of intracellular bacterial pathogens. Microbes Infect 5, 621-627.

Chakravortty, D., Hansen-Wester, I. \& Hensel, M. (2002). Salmonella pathogenicity island 2 mediates protection of intracellular Salmonella from reactive nitrogen intermediates. J Exp Med 195, 1155-1166.

Cherayil, B. J. \& Antos, D. (2001). Inducible nitric oxide synthase and Salmonella infection. Microbes Infect 3, 771-776.

Clegg, S., Yu, F., Griffiths, L. \& Cole, J. A. (2002). The roles of the polytopic membrane proteins NarK, NarU and NirC in Escherichia coli K-12: two nitrate and three nitrite transporters. Mol Microbiol 44, 143-155.

Datsenko, K. A. \& Wanner, B. L. (2000). One-step inactivation of chromosomal genes in Escherichia coli K-12 using PCR products. Proc Natl Acad Sci U S A 97, 6640-6645.

De Groote, M. A., Granger, D., Xu, Y., Campbell, G., Prince, R. \& Fang, F. C. (1995). Genetic and redox determinants of nitric oxide cytotoxicity in a Salmonella typhimurium model. Proc Natl Acad Sci U S A 92, 6399-6403.

Deiwick, J., Nikolaus, T., Erdogan, S. \& Hensel, M. (1999). Environmental regulation of Salmonella pathogenicity island 2 gene expression. Mol Microbiol 31, 1759-1773.
Evans, T. G., Thai, L., Granger, D. L. \& Hibbs, J. B., Jr (1993). Effect of in vivo inhibition of nitric oxide production in murine leishmaniasis. J Immunol 151, 907-915.

Fields, P. I., Swanson, R. V., Haidaris, C. G. \& Heffron, F. (1986). Mutants of Salmonella typhimurium that cannot survive within the macrophage are avirulent. Proc Natl Acad Sci U S A 83, 5189-5193.

Gilberthorpe, N. J., Lee, M. E., Stevanin, T. M., Read, R. C. \& Poole, R. K. (2007). NsrR: a key regulator circumventing Salmonella enterica serovar Typhimurium oxidative and nitrosative stress in vitro and in IFN- $\gamma$-stimulated J774.2 macrophages. Microbiology 153, 1756-1771.

Hanano, R. \& Kaufmann, S. H. (1995). Nitric oxide production and mycobacterial growth inhibition by murine alveolar macrophages: the sequence of rIFN-gamma stimulation and Mycobacterium bovis BCG infection determines macrophage activation. Immunol Lett 45, 23-27.

Hensel, M. (2000). Salmonella pathogenicity island 2. Mol Microbiol 36, 1015-1023.

Kawakami, K., Zhang, T., Qureshi, M. H. \& Saito, A. (1997). Cryptococcus neoformans inhibits nitric oxide production by murine peritoneal macrophages stimulated with interferon-gamma and lipopolysaccharide. Cell Immunol 180, 47-54.

Kharitonov, V. G., Sundquist, A. R. \& Sharma, V. S. (1994). Kinetics of nitric oxide autoxidation in aqueous solution. J Biol Chem 269, 5881-5883.

Kim, C. C., Monack, D. \& Falkow, S. (2003). Modulation of virulence by two acidified nitrite-responsive loci of Salmonella enterica serovar Typhimurium. Infect Immun 71, 3196-3205.

Lahiri, A., Das, P. \& Chakravortty, D. (2008a). Arginase modulates Salmonella induced nitric oxide production in RAW264.7 macrophages and is required for Salmonella pathogenesis in mice model of infection. Microbes Infect 10, 1166-1174.

Lahiri, A., Das, P. \& Chakravortty, D. (2008b). The LysR-type transcriptional regulator Hrg counteracts phagocyte oxidative burst and imparts survival advantage to Salmonella enterica serovar Typhimurium. Microbiology 154, 2837-2846.

Lindgren, S. W., Stojiljkovic, I. \& Heffron, F. (1996). Macrophage killing is an essential virulence mechanism of Salmonella typhimurium. Proc Natl Acad Sci U S A 93, 4197-4201.

MacMicking, J., Xie, Q. W. \& Nathan, C. (1997). Nitric oxide and macrophage function. Annu Rev Immunol 15, 323-350.

Mastroeni, P., Vazquez-Torres, A., Fang, F. C., Xu, Y., Khan, S., Hormaeche, C. E. \& Dougan, G. (2000). Antimicrobial actions of the $\mathrm{NADPH}$ phagocyte oxidase and inducible nitric oxide synthase in experimental salmonellosis. II. Effects on microbial proliferation and host survival in vivo. J Exp Med 192, 237-248.

McCollister, B. D., Bourret, T. J., Gill, R., Jones-Carson, J. \& VazquezTorres, A. (2005). Repression of SPI2 transcription by nitric oxideproducing, IFN $\gamma$-activated macrophages promotes maturation of Salmonella phagosomes. J Exp Med 202, 625-635.

Miller, S. I., Hohmann, E. L. \& Pegues, D. A. (1995). Salmonella (Including Salmonella Typhi), vol. 2. New York: Churchill Livingston.

Mills, P. C., Rowley, G., Spiro, S., Hinton, J. C. \& Richardson, D. J. (2008). A combination of cytochrome $c$ nitrite reductase (NrfA) and flavorubredoxin (NorV) protects Salmonella enterica serovar Typhimurium against killing by $\mathrm{NO}$ in anoxic environments. Microbiology 154, 1218-1228.

Miranda, K. M., Espey, M. G. \& Wink, D. A. (2001). A rapid, simple spectrophotometric method for simultaneous detection of nitrate and nitrite. Nitric Oxide 5, 62-71.

Miyagi, K., Kawakami, K. \& Saito, A. (1997). Role of reactive nitrogen and oxygen intermediates in gamma interferon-stimulated murine 
macrophage bactericidal activity against Burkholderia pseudomallei. Infect Immun 65, 4108-4113.

Nairz, M., Fritsche, G., Brunner, P., Talasz, H., Hantke, K. \& Weiss, G. (2008). Interferon-gamma limits the availability of iron for intramacrophage Salmonella typhimurium. Eur J Immunol 38, 1923-1936.

Ochman, H., Soncini, F. C., Solomon, F. \& Groisman, E. A. (1996). Identification of a pathogenicity island required for Salmonella survival in host cells. Proc Natl Acad Sci U S A 93, 7800-7804.

Pacher, P. \& Szabo, C. (2006). Role of peroxynitrite in the pathogenesis of cardiovascular complications of diabetes. Curr Opin Pharmacol 6, 136-141.

Pakianathan, D. R. \& Kuhn, R. E. (1994). Trypanosoma cruzi affects nitric oxide production by murine peritoneal macrophages. J Parasitol 80, 432-437.

Pan, Q., Kravchenko, V., Katz, A., Huang, S., Ii, M., Mathison, J. C., Kobayashi, K., Flavell, R. A., Schreiber, R. D. \& other authors (2006). $\mathrm{NF}-\kappa$ B-inducing kinase regulates selected gene expression in the Nod2 signaling pathway. Infect Immun 74, 2121-2127.

Proudfoot, L., O'Donnell, C. A. \& Liew, F. Y. (1995). Glycoinositolphospholipids of Leishmania major inhibit nitric oxide synthesis and reduce leishmanicidal activity in murine macrophages. Eur J Immunol 25, 745-750.

Proudfoot, L., Nikolaev, A. V., Feng, G. J., Wei, W. Q., Ferguson, M. A., Brimacombe, J. S. \& Liew, F. Y. (1996). Regulation of the expression of nitric oxide synthase and leishmanicidal activity by glycoconjugates of Leishmania lipophosphoglycan in murine macrophages. Proc Natl Acad Sci U S A 93, 10984-10989.

Ramarathinam, L., Shaban, R. A., Niesel, D. W. \& Klimpel, G. R. (1991). Interferon gamma (IFN- $\gamma$ ) production by gut-associated lymphoid tissue and spleen following oral Salmonella typhimurium challenge. Microb Pathog 11, 347-356.

Rottenberg, M. E., Gigliotti Rothfuchs, A., Gigliotti, D., Ceausu, M., Une, C., Levitsky, V. \& Wigzell, H. (2000). Regulation and role of IFNgamma in the innate resistance to infection with Chlamydia pneumoniae. J Immunol 164, 4812-4818.

Shea, J. E., Hensel, M., Gleeson, C. \& Holden, D. W. (1996). Identification of a virulence locus encoding a second type III secretion system in Salmonella typhimurium. Proc Natl Acad Sci U S A 93, 2593-2597.

Stuehr, D. J. (1997). Structure-function aspects in the nitric oxide synthases. Annu Rev Pharmacol Toxicol 37, 339-359.

Suzuki, Y., Orellana, M. A., Schreiber, R. D. \& Remington, J. S. (1988). Interferon-gamma: the major mediator of resistance against Toxoplasma gondii. Science 240, 516-518.

Szeto, J., Namolovan, A., Osborne, S. E., Coombes, B. K. \& Brumell, J. H. (2009). Salmonella-containing vacuoles display centrifugal movement associated with cell-to-cell transfer in epithelial cells. Infect Immun 77, 996-1007.

Uchiya, K. \& Nikai, T. (2005). Salmonella pathogenicity island 2dependent expression of suppressor of cytokine signaling 3 in macrophages. Infect Immun 73, 5587-5594.

Uchiya, K., Barbieri, M. A., Funato, K., Shah, A. H., Stahl, P. D. \& Groisman, E. A. (1999). A Salmonella virulence protein that inhibits cellular trafficking. EMBO J 18, 3924-3933.

Vazquez-Torres, A., Jones-Carson, J., Mastroeni, P., Ischiropoulos, $\mathrm{H}$. \& Fang, F. C. (2000). Antimicrobial actions of the NADPH phagocyte oxidase and inducible nitric oxide synthase in experimental salmonellosis. I. Effects on microbial killing by activated peritoneal macrophages in vitro. J Exp Med 192, 227-236.

Waterman, S. R. \& Holden, D. W. (2003). Functions and effectors of the Salmonella pathogenicity island 2 type III secretion system. Cell Microbiol 5, 501-511.

Wu, Q. \& Stewart, V. (1998). NasFED proteins mediate assimilatory nitrate and nitrite transport in Klebsiella oxytoca (pneumoniae) M5al. J Bacteriol 180, 1311-1322.

Xie, Q. \& Nathan, C. (1994). The high-output nitric oxide pathway: role and regulation. J Leukoc Biol 56, 576-582.

Yu, X. J., Ruiz-Albert, J., Unsworth, K. E., Garvis, S., Liu, M. \& Holden, D. W. (2002). SpiC is required for secretion of Salmonella pathogenicity island 2 type III secretion system proteins. Cell Microbiol 4, 531-540.

Edited by: V. J. Cid 